Parvaneh Shamsipour Dehkordi ${ }^{*}$, Parisa Hejazi², Somaye Babaei ${ }^{3}$

\title{
COMPARISON OF MENTAL HEALTH AND QUALITY OF LIFE IN ACTIVE AND NON ACTIVE ELDER'S FEMALE I N WEST REGI ON OF TEHRAN
}

\begin{abstract}
Introduction: The elder people are the rising population groups of the present societies, who based on the age pyramid, have acquired a daily increasing attention. In this case, every decision making and scheduling concerning this issue needs detailed, subjective and scientific based recognition. Thus, the purpose of this study was the Comparison of mental health and quality of life in Active and non-active Elder's female in west region of Tehran.

Method: This was a retrospective study. Through randomly sampling method, the statistical sample of this research encompassed a group of 280 (140 active and 140 non-active) elder female with an age range of 60 to 85 years, half of whom were active physically and the other half lacked physical activity. The research tools included the questionnaires for personal characteristics, the Yale physical activity, Goldberg Mental health questionnaire and Leipard quality of life questionnaire. Data were analyzed using descriptive statistics, and Multivariate ANOVA method.
\end{abstract}

Results: The results showed that levels of mental health and quality of life were higher in active elders than non-active elders. Active female elders were significantly higher in mental health and quality of life than their non-active female counterparts.

Conclusion: Regarding the results, mental health and quality of life are related meaningfully indicating that elder people should be considered with programs as vulnerable group. The researchers suggest health authorities to provide this group with programs and facilities for promotion of their physical functioning, and also suggest prospective studies to be conducted in this issue.

Key words: Mental Health, Quality of Life, elder female, physical activity

"Department of Physical Education and Sport Sciences, Alzahra University. Tehran, Iran.

Department of Physical Education and Sport Sciences, Alzahra University. Tehran, Iran.

3 Department of Physical Education and Sport Sciences, Alzahra University. Tehran, Iran. 


\section{Introduction}

Aging is a natural route and critical phenomena that occur in all living organisms and the physiological and psychological changes occur in the body (1). Considerable progress in modern societies, improved living conditions, proper nutrition, medical and health care, and consequently the increase in mean age, increasing elderly population and the problems associated with it are known as one of the major causes of interest to study elderly (2). The vast advances in technology have significantly influenced the style of many communities (3). According to Cox (2007), industrialized societies and consequently reduced mobility and physical activity in the population have emerged the need to exercise, and attract great attention to the sport, especially the role of psychological issues in sport (4). Thus, aging is a critical period of human life and addressing the social needs of this stage is a necessity (5). Due to advances in health and longer life expectancy, elderly expectations have changed dramatically about their lifestyle, environment, and society and also about service providers in the field of physical education and sport in recent years (6). Therefore, the range of physical activity is necessary as one of the most important needs in this period to increase mental health, functional capacity, quality of life and independence in this population (7). To be able to live many years, quality of life and mental health in the community should be maintained at a high level (8).

Lowton (1993) stated that a high quality of life can be a "good life" interpretation, which includes four goals of environmental factors, behavioral competence, quality of life and well-being. Quality of life is linked directly to the satisfaction of people in their lives. Therefore, the quality of life should be a coordinated set of satisfaction with aspects of physics, psychology and the social sense (9). The relationship between physical activity and exercise programs for the elderly improves muscle function and quality of life $(10,11)$. According to researchers, many issues and problems that occur in older physiologically are effective in reducing the quality of life in old age. As life expectancy increases, the importance of health promotion behaviors becomes more obvious with regard to maintaining functional independence and improving quality of life day to day (12).

The most important issue in the promotion of elderly mental health and quality of life is to maintain their independence and physical activity, cognitive and continue their lives as active (13). Research findings have shown that a sufficient level of physical activity leads to improved mental health in the elderly. Regular physical activity also leads to better physical health, anxiety and insomnia, social dysfunction and severe depression in the elderly (14). Physical activity is one of the most effective methods of prevention of mental disorders and physical aging, so that an inverse relationship between physical activity and symptoms related to the future of mental disorders has been reported (15). The researchers believe that the increase in leisure-time physical activity (LTPA) and decrease in leisure-time sedentary behavior (LTSB) are indepen- 
dently associated with improved health-related quality of life (HR QoL) in the elderly. Especially doing more LTPA has shown a positive linear trend between physical functioning, vitality, social functioning, emotional role and mental health (3).

Koltyn (2001) conducted a study on a group of elderly women over 65 in the United States to understand theeffect of exercise on quality of life, and reached to the conclusion that Levels of physical activity are significantly associated with quality of life and physical health of the elderly (16). Research by Wood et al (2008) showed that exercise causes a significant increase in the quality of life (12). Fiz Grard (1985) also believes that the lack of mobility of the elderly causes a significant decline in physical abilities, functional capacity and happiness. Physical activity programs can be a hedge against this decline. The correct application of physical activity can make considerable progress in the quality of life. Research has shown that exercise not only improves the social, economic and health in old age role-playing and quality of life of older people, but also the promotion of mental health in the community is also effective (17).

According the effect of physical exercise on depressive symptoms, Motl et al (2005) stated that Intervention sustained exercise reduces symptoms of depression in the elderly sedentary and physical self-esteem as a potential moderator of the effect (18). Also Kokkonen et al (2014) in their study showed that exercise training for 12 weeks resulted in an improvement in functional capacity, physical strength, cognitive performance (performance, processing speed and working memory) and improving the quality of life in the elderly than in the control group (19). Krawczynski, Olszewski and Fontaine (2000) found that physical activity can increase happiness, self-esteem, depression and loss of life and a high correlation between physical activity and mental health were reported (20).

According to research about the role of physical activity and exercise on quality of life and mental health and considering the specific characteristics of the elderly and the effect of exercise on their lives, researchers sought to compare the quality of life and mental health of active and non active elderly women. Elderly sensitivity and increasing aging population on the one hand, on the other hand, society need to acquire specific skills and psychosocial quality of life in this era is one of the necessities of the study because the quality of life plays an important role in economic development, social and cultural community and are considered the fundamental aspects of personal growth and mental health. If the role of physical activity in this study could be determined; it is obvious that the present study uses the results and guidelines, Social institutions, by creating an environment suitable exercise for seniors, and active and effective role in society and to provide, maintain and promote physical health and psychosocial seniors to enjoy a better quality of life and increase their motivation to improve social relationships and deal with problems and ensure better physical and mental health and reduce drug costs for seniors in the evolution and development of society. 


\section{Method}

The study is causal - comparative. Thus, two groups of elderly active and non-active women were compared in terms of mental health and quality of life variables.

Population, sample and sampling methods: The study population consisted of all women living in families in Tehran in 2013. Sample was 140 healthy elderly woman non-active in any physical activity and sport participation but having the ability to perform normal work day without dependence on others, and 140 active elderly woman who had physical activity for 3 consecutive years, 3 days a week at least for 1 hour every day and took part in the exercise group. The study was a multi-stage sampling. Thus, regions 2, 6, 18 and 21 from different regions of the West of Tehran (which includes 2, 5, 6, 9, 18, 21 and 22, respectively) were randomly selected. The public places (mosques, parks, sports facilities and shopping centers) and the homes in this area were identified as 2 mosques in the area, 2 parks, 2 sport centers and 2 shopping centers were randomly selected. Then, 4 questioners, who had been trained completing the questionnaire, attended in these places, and in the end, any public place elderly who have the research profiles were participated.

Among elderly persons, 280 people were selected (140 active and 140 non-active elderly) who had the criteria for the study. Criteria for elderly entering to the research with regard to the existing research literature include having at least 60 years of age, tend to fill out the questionnaire, the ability to stand without assistive device, such as a lack of visual and proprioceptive sensory loss, lack of structural defects, No neurologic deficits (stroke, Parkinson's disease, paralysis), cardiovascular disorders (acute myocardial infarction, acute heart failure and uncontrolled hypertension), not having been diagnosed with anxiety disorders, lack of stable chronic diseases (diabetes, cancer), no Severe congenital defects and disorders of the muscle - skeletal range. The elderly were mentally alert and able to respond to their questions.

To determine whether elderly women are active or non active was used demographic questionnaire and Yale physical activity questionnaire. The Yale physical activity questionnaire consists of 7 questions and the three components of activity, activity and energy expenditure during activity assesses. The questionnaire for the elderly within a week of activities that would normally have done in the past month in terms of time and energy consuming responded by activity was calculated. After calculating the energy in kilocalories per week, it was converted into a MET unit. Seniors whose activity is lower than the 3000 MET of a week, the disabled and seniors older than 3000 MET had physical activity per week were classified as active aging. In the research, reliability coefficients of the questionnaire (53\%) and small scale reliability coefficients were reported $0 / 55$ to $0 / 68$.

To assess the mental health was used Goldberg and Hillier mental health questionnaire that containing 28 questions and four subscales somatic symptoms, anxiety, social dysfunction and depression. The total score of the questionnaire, which measures 
the overall mental health of the elderly is lower score is better mental health. In the research, reliability coefficients of the questionnaire $(65 \%)$ and small scale reliability coefficients were reported 0.62 to 0.77 .

To assess the mental health was used Leipard quality of life questionnaire. The questionnaire consists of 31 multiple-choice questions with a score between zero and three, that quality of life in seven dimensions: physical function (5 items), self-care (6 years), depression and anxiety (4 items), mental functioning (5 items), sexual function (2 items) and life satisfaction (6 items) investigated. In the present study was to determine the reliability and Leipard quality of life of Cronbach's alpha and split-half coefficients were used to 0/93 and 0/88 respectively. Total score of overall quality of life questionnaire that measures the quality of life of the elderly, the higher the score the better teaching.

Finally, after completing the questionnaire collected demographic, mental health and quality of life, to analyze the data, descriptive statistics such as mean, standard deviation and multivariate analysis was performed using SPSS software.

\section{Results}

Descriptive findings of this study are presented in Tables 1 and 2. Table 1 shows the mean and standard deviation scores of elderly women in the areas of mental health, active and non active states. As the results presented in Table 1, show that mental health scores of the components of somatization, anxiety, social dysfunction and depression in the elderly woman, elderly women than non active.

Table 1.Mean and standard deviation scores of mental health and components in active and inactive elderly women

\begin{tabular}{lcccc}
\hline \multicolumn{1}{c}{ Group } & \multicolumn{2}{c}{$\begin{array}{c}\text { Active older } \\
\text { Standard Deviation }\end{array}$} & Mean & Non active older \\
Statistics $\longrightarrow$ & mean & & & \\
Variable & & & 63.62 & 7.78 \\
$\quad$ & & 9.34 & 11.66 & 4.47 \\
General Mental Health & 40.78 & 3.22 & 17.436 & 5.23 \\
Physical syndrome & 7.03 & 5.44 & 3.98 & 8.57 \\
Anxiety & 12.59 & 14.77 & 3.56 & 12.521 \\
Social dysfunction & 7.06 & 20.352 & & \\
Depression & 2.80 & &
\end{tabular}

Table 2 shows the mean and standard deviation scores and quality of life in elderly women with active and non active components as indicated. The results in Table 2 show that the overall quality of life scores and physical characteristics, care, anxiety and depression, social, psychological, and sexual satisfaction in active elderly women than elderly woman is passive. 
Table 2. Mean and standard deviation scores of Quality of Life and components in active and non active elderly women

\begin{tabular}{lcccc}
\hline \multicolumn{1}{c}{ Group } & \multicolumn{2}{c}{$\begin{array}{c}\text { Active older } \\
\text { Standard Deviation }\end{array}$} & Mean active older \\
Statistics \\
$\begin{array}{l}\text { Variable } \\
\qquad\end{array}$ & mean & & & \\
$\quad$ & & & & \\
Quality of life & 79.86 & 17.08 & 47.75 & 14.33 \\
Physical & 10.80 & 3.88 & 7.07 & 1.92 \\
Self-care & 20.32 & 4.55 & 11.29 & 7.24 \\
Anxiety and depression & 9.42 & 4.21 & 6.45 & 3.28 \\
Social & 9.59 & 6.27 & 6.17 & 3.71 \\
Mental & 12.75 & 6.38 & 8.90 & 7.22 \\
Sexual & 3.34 & 6.06 & 5.79 & 4.03 \\
\hline
\end{tabular}

Multivariate analysis of variance in table 3 for the mental health and quality of life scores for active and inactive elderly woman is shown for Wilks Lambda test with degrees of freedom $(\mathrm{df}=1)$ and significant level $(\mathrm{P}=0.001)$. Aged between active and inactive variables in the study, there was a significant difference. As can be seen in Table 1, both active and non-active were in terms of mental health among the elderly. Also, according to the results presented in table 3, between the active and inactive elderly women in terms of quality of life were significantly different. According to quality of life average for elderly woman than the quality of life average in sedentary elderly women in table 2, elderly woman has a higher quality of life.

Table 3. Analysis of variance (MANOVA) mental health and quality of life of elderly women in active and non active

\begin{tabular}{rrrrrr}
\hline Variables & Total squares & df & Mean square & $F$ & sig \\
Mental Health & 37031.863 & 1 & 37031.863 & 496.720 & 0.001 \\
Quality of life & 73261.901 & 1 & 73216.901 & 2208.526 & 0.001 \\
\hline
\end{tabular}

Note: F ratio of variable to Wilks Lambda test is 1324/206, $\mathrm{P}<0.001$.

\section{Discussion}

The purpose of this study was to compare the mental health and quality of life in active and non active elder's female in West region of Tehran. The results showed that the total mental health score and component scores of physical syndrome, anxiety, social dysfunction and depression in the active elder's female was lower than non active elder's female, which according to the grading scale of mental health showed higher mental health of elderly woman is active. 
The results of this research with the results Siegenthaler (1999), Hilleras et al (2007) is in line $(21,22)$. They concluded in their research that high levels of physical fitness (physical activity) is reducing anxiety, depression and social dysfunction in the elderly, and makes mental health, self-esteem, and social skills in elders increase. Also, Griffiths, et al (2014), Motl et al (2005) and Matlabi (2014) Showed that physical activity on mental health index is effective $(14,15,18)$. Recent studies have also stated that physical activity and exercise, by reducing the fear of falling, improve self-sufficiency and mental health in the elderly to improve strength, balance, muscle function and mental health in the population (23, 24). Also Dechamps et al (2007) and Patil et al (2013) relationship between quality of life, physical activity, health and functionality with the fear of falling in older women with a previous history of falls reported. Because of the possible positive effects of physical activity on mental health can be positively associated with psychological effects such as self-esteem, a sense of hope and self-esteem more, stronger social relationships, ability to adapt and cope with problems which part of it is due to the nature of physical activity and participation in physical activity is obtained $(25,26)$.

Also, results showed that the total quality of life score and component scores of physical factors, self-care, anxiety and depression, social, psychological, sexual and life satisfaction is higher among the active elderly woman. The results obtained in this research with results of Becker and Tenenbaum (2005); Hegbom, et al (2007); Maculey (2005); Matlabi (2014); langlois, et al (2013); and Brown, et al (2014) were similar $(2,10,14,27,28,29)$.

Their researches showed that exercise has a positive effect on the quality of life of older people. Because of the possible positive effects of physical activity on quality of life can be that physical activity reduces the activity limitations, more independent, happy and successful life and the increasing role and thus lead to increased quality of life and sense of well-being in the elderly (14). Therefore, it can be deduced that the elderly with lower mental health and lower quality of life by addressing physical activity as an environmental experience can somehow ease their personality conflicts and achieve better mental and social growth find (30). Kokkonen, et al (2001) and Maculey (2005) also suggests that physical activity reduces the withdrawn, somatic complaints, depression and mental disorders and quality of life and life expectancy is increasing $(19,28)$.

The most important factors that can lead to reduced physical activity and physical fitness of elderly people, is the culture anti-aging. The cause is frustration and lack of adequate access to the elderly. Accordingly, in various countries, particularly older people, and older women are false labels being sick, weak and unable to eat, and factors such as retirement and the loss of a spouse as a result of financial losses and lack of movement immobility caused and reduce the sense of self efficacy in this class. But fun and refreshing mobility exercise causes the higher stratum of society feel safe living in the community and mental health, their health and quality of life increase. 


\section{Conclusion}

According to the results of previous studies and the results of this study showed that Physical activity and sport participation teaser is one of the important factors that modulate the unfortunate crises at all stages of human development and solidarity and to strengthen the personality characteristics, mental health, physical, social adjustment $(14,19,31)$ and improving the quality of life of the elderly (26). Thus, with the support of physical education programs, promotion and advertising anti-aging effects of physical and mental health nursing and community policies and strategies targeted at encouraging long-term planning for young officials that future seniors are targeted and short-term investments For the elderly the most vulnerable in the near future make up most of the population, could be delayed aging, older, younger and a better return to the community, cultural-social thinking in order to combat the old anti-aging culture and reverse the cycle of physical exercise and thereby strengthen internal cohesion and foster a sense of perfection in which the mental system.

As the results of research studies show physical activity, sports and entertainment, happy and satisfying life for seniors creates. It is recommended to design appropriate strategies for exercise and physical activity, especially the activity of mass at the center of activity for the elderly, elderly care centers, complexes, parks and public places as a factor for increasing the spirit of modernity and diversity of desire, hope and confidence future mass participation and group work used in the elderly, in order to meet the needs and expectations of the elderly (legal aspects) and benefit the quality of life of older people in economic, social, health, physical, psychological, cultural and They contribute to the development of the country, to the needs of civil society in the fields of reconstruction and eradication of poverty in the aspects of cultural, social and economic (aspects of responsibility) should be considered.

Acknowledgment: The authors express their thanks to the questioners and seniors participated in this study for patience and also expressed confidence the researcher. We hope that the results of this study may help older people to live better society.

\section{References}

1. Bengston, V, et al. Paradoxes of families and ageing. Hard Book of Aging and The Social Sciences. New York: Academic Press, 1996.

2. Becker, BJ., Tenenbaum, G. Physical activity and psychological well-being in advanced age. Zinman College of Physical Education and Sciences, 2005, 20 (2): 272-284.

3. Balboa-Castillo, T., León-Muñoz, L. M., Graciani, A., Rodríguez-Artalejo, F., GuallarCastillón, P. Longitudinal association of physical activity and sedentary behavior during leisure time with health-related quality of life in community-dwelling older adults. Health Quality Life Outcomes, 2011, 9: 47.

4. Cox, RH. Sport psychology, concepts and application. New York: McGraw Hill, 2007. 
5. Vahdaninia, MS., Goshtasbi, A., Maftoon F. Health related quality of life in elderly people. Population Survey. Payesh, 2005, 4 (2): 113-120.

6. Walter, T. Physical activity and quality of life in older adults. Journals of Gerontology Series Sciences Sport of the elderly. Kinesiology, 2004, (36): 98-103.

7. Smazzeo, R., Tanaka, H. Exercise prescription for the erderl. Sport Medicin, 2001, 31(11): 809-818.

8. Hisazo, O., Hiroshi, S., Shuichiro, W., Shu, K., Suzuki, T. The relationship between psychological well-being and physical functionting in japanese urban and rural older adults. Journal of aging and physical activity, 2000, (8): 140-147.

9. Lowtan, MP. Environment and other determinants of well-being in older people. The Gerontologist, 1983, (23): 349-357.

10. Brown, DR., Carroll, DD., Workman, LM., Carlson, SA., Brown, DW. Physical activity and health-related quality of life: US adults with and without limitations. Quality of Life Research, 2014, 23 (10): 2673-2680.

11. Pereira, FF., Dantas, EH., Monteiro, N., Novaes, J., Junior, AG. Effect of strength training on the life of quality in elderly women. Fit Perf J, 2006, 5 (6).

12. Wood, L., Peat, G., Thomas, E., Hay, EM., Sim J. Associations between physical examination and self-reported physical function in older community-dwelling adults with knee pain. Phys There, 2008, 88 (1): 33-42.

13. Patterson, SL., Rodgers, MM., Macko, RF., Forrester, LW. Effect of treadmill exercise training on spatial and temporal gaint parameters in subjects with chronic stroke: A preliminary report. J Rehabil Res Dev, 2008, 45 (2): 222-228.

14. Matlabi, H., Shaghaghi, A., \& Amiri, S. A Pilot Physical Activity Initiative to Improve Mental Health Status amongst Iranian Institutionalized Older People. Health promotion perspectives, 2014, 4(1): 68.

15. Griffiths, A., Kouvonen, A., Pentti, J., Oksanen, T., Virtanen, M., Salo, P., Vahtera, J. Association of physical activity with future mental health in older, mid-life and younger women. The European Journal of Public Health, 2014, 199.

16. Koltyn, K.F. The association between physical activity and quality of life in older women. department of kinesiology, wisconism, USA. 2001, 11 (6): 471-480.

17. Fiz Grard, P.L. Exercise for the elderly. medicine Clint north American. 1985, 69(1): 189-196.

18. Motl, R.W., Konopack, J. F., McAuley, E., Elavsky, S., Jerome, G. J., Marquez, D. X. Depressive symptoms among older adults: long-term reduction after a physical activity intervention. Journal of behavioral medicine, 2005, 28(4), 385-394.

19. Kokkonen, M., Pulkkinen, L. Extraversion and neuroticism as antecedents of emotion regulation and deregulation in adulthood. New York, Basic books. 2014.

20. Krawczynski, M., Olszewski, H. Psychological well-being associated with a physical activity program for persons over 60 years old. Psychology of Sport and Exercise, 2000, 1: 57-63.

21. Siegenthaler, KL. Sweating with the oldies: activity and successful aging. Arlington: Parks and Recreation Association, 1999. 
22. Hilleras, PK., Jorm, AF., Herlitz, A., Windblad, B. Activity patterns in very old people: A survey of cognitively intact subjects aged 90 years or elders. Age and aging: Oxford, 1999, 28(2): 147-152.

23. Zhang, JG., Ishikawa, TK., Yamazaki, H., Morita, T., Ohta, T. The effects of tai chi chuan on physiological function and fear of falling in the less robust elderly: An intervention study for preventing falls. Archives of Gerontology and Geriatrics, 2005.

24. Li, F., Harmer, P., Fisher, KJ., McAuley, E. Tai Chi: improving functional balance and predicting subsequent falls in older person. Medicin and science in sport and exercise, 2004, 36 (12): 2046-2052.

25. Dechamps, A., Lafont, L., Bourdel-marchasson, I. Effects of tai chi exercise on selfefficacy and psychological health. European Review of Aging and Physical Activity, 2007, 4: 25-32.

26. Patil, R., Uusi-Rasi, K., Kannus, P., Karinkanta, S., \& Sievänen, H. Concern about falling in older women with a history of falls: associations with health, functional ability, physical activity and quality of life. Gerontology, 2014, 60(1), 22-30.

27. Hegbom, F., Stavem, K., Sire, S., Heldal, M., Orning, OM., Gjesdal, K. Effect of shortterm exercise training on quality of life elderly person, 2007, 116 (1): 272-284.

28. Maculey, E. Physical activity and quality of life in older adults: efficacy-esteem and effective influences, 2005, 213-220.

29. Langlois, F., Vu, T. T. M., Chassé, K., Dupuis, G., Kergoat, M. J., \& Bherer, L. Benefits of physical exercise training on cognition and quality of life in frail older adults. The Journals of Gerontology Series B: Psychological Sciences and Social Sciences, 2013, 68 (3): 400-404.

30. Payne, G., Isaacs. "Human motor development: a lifespan approach". Mc Grow Hill, $7^{\text {th }} .2008$.

31. Dishman, RK. Physical activity and public health. Mental Health Quest, 1995; 47 (3): 362-385. 